\title{
Involuntary orofacial movements in hospitalised patients with mental handicap or epilepsy: relationship to developmental/intellectual deficit and presence or absence of long-term exposure to neuroleptics
}

\author{
HANAFY A YOUSSEF, * JOHN L WADDINGTON† \\ From St Davnet's Hospital, Monaghan,* and Department of Clinical Pharmacology, Royal College of Surgeons \\ in Ireland, St Stephen's Green, Dublin $\dagger$, Ireland
}

SUMMARY Among 42 adult patients with mental handicap who had received treatment with neuroleptic drugs, the prevalence of orofacial dyskinesia increased with age and those with such involuntary movements were characterised by a considerably greater degree of mental handicap. Similar associations were found among a group of 15 patients with epilepsy. Two of seven other mentally handicapped patients and one of eight other epileptic patients showed indistinguishable orofacial dyskinesia, despite no record of them having received neuroleptic drugs.

Recent studies in schizophrenia ${ }^{1-4}$ and bipolar affective disorder ${ }^{4} 5$ have revived interest in the older hypothesis ${ }^{6}$ that there may be some relationship between the extent of organic brain dysfunction and the emergence of involuntary movements during longterm neuroleptic treatment. Clearly, if such associations are to form the basis of a more general hypothesis of vulnerability to tardive dyskinesia, ${ }^{7}$ they should be demonstrable in other disorders. The present study examined these notions in a population of the adult mentally handicapped, by contrasting developmental/intellectual impairment with medication history. Additionally, comparisons were made with a population of similarly hospitalised adult patients with epilepsy.

\section{Method}

Forty nine mentally handicapped patients in St Davnet's Hospital (31 male, 18 female; age range 16-76 years) were studied; excluded were patients with epilepsy, other neurological disorders, psychotic features, or brain damage.

\footnotetext{
Address for reprint requests: Dr John L Waddington, Department of Clinical Pharmacology, Royal College of Surgeons in Ireland, St Stephen's Green, Dublin 2, Ireland.
}

Received 30 October 1987 and in revised form 16 February 1988. Accepted 1 March 1988
Movement disorder was evaluated using the Abnormal Involuntary Movement Scale. ${ }^{8}$ It was necessary to take into consideration potential problems created by the multiplicity of stereotyped, ritualistic, manneristic and imitative movements, of many body regions, that may be shown by the mentally handicapped. ${ }^{910}$ Therefore, categorisation of patients by movement status was based here on a much more conservative application of the gradations of the rating scale than we have previously adopted, and was restricted to orofacial movements. ${ }^{3}$

Case notes were reviewed to extract demographic details and medication history. For specification of degree of mental handicap, the four severity criteria (mild, moderate, severe, profound) of DSM-III ${ }^{911}$ were applied to the developmental history and current clinical state of each patient, occasionally supplemented by two intermediate categories (mild-moderate, moderate-severe) to reflect the inherent difficulties in precision immediately around the nominal boundaries between gradations. These were transformed into an ordinal scale as follows: Mild $=1(n=13)$; mildmoderate $=2(n=4)$; moderate $=3(n=13)$; moderatesevere $=4 \quad(n=5) ;$ severe $=5 \quad(n=12) ;$ profound $=6$ $(\mathrm{n}=2)$.

Similar procedures were applied to a heterogeneous group of 28 inpatients with epilepsy ( 20 male, 8 female; age range 25-90 years) who were resident in the same hospital wards.

\section{Results}

Forty two of the 49 patients with mental handicap had 
Table Characteristics of those mentally handicapped inpatients treated with neuroleptics, in relation to the presence or absence of involuntary movements (IM)

\begin{tabular}{|c|c|c|}
\hline & $I M$ absent & $I M$ present \\
\hline Number & $26(19 \mathrm{M}, 7 \mathrm{~F})$ & $11(8 \mathrm{M}, 3 \mathrm{~F})$ \\
\hline $\begin{array}{l}\text { Age } \\
\text { Duration of hospitalisation }\end{array}$ & $\begin{array}{l}49 \cdot 0, \text { SD } 10.5 \\
21.9, \text { SD } 10.8\end{array}$ & $\begin{array}{l}50 \cdot 9, \text { SD } 10 \cdot 0 \\
28 \cdot 3 \text {, SD } 11 \cdot 1\end{array}$ \\
\hline Duration of neuroleptics & $11 \cdot 7$, SD $8 \cdot 7$ & $17 \cdot 0$, SD $10 \cdot 3$ \\
\hline Average neuroleptic doset & 240, SD 218 & 289, SD 155 \\
\hline Current use of neuroleptics & $18 / 26$ & $6 / 11$ \\
\hline Current neuroleptic dose $†$ & 308, SD 464 & 341, SD 355 \\
\hline Exposure to anticholinergics & $14 / 26$ & $10 / 11$ \\
\hline Duration of anticholinergics & $8 \cdot 2$, SD $7 \cdot 6$ & $9 \cdot 1$, SD $7 \cdot 2$ \\
\hline Current use of anticholinergics & $8 / 26$ & $4 / 11$ \\
\hline Degree of mental handicap & $2 \cdot 5$, SD 1.4 & $4 \cdot 1$, SD $1 \cdot 3 *$ \\
\hline
\end{tabular}

received long-term treatment with neuroleptic drugs (durations $0 \cdot 6-27 \cdot 7$ years). Of these, $11(26 \cdot 2 \%)$ showed typical orofacial dyskinesia; there was no significant difference between the prevalence of such dyskinesia in males $(8 / 28 ; 28.6 \%)$ and females $(3 / 14$; $21.4 \%$ ). The prevalence of orofacial dyskinesia increased with age, as follows: $<35$ years, $0 / 5(0 \%)$; $35-54$ years, $7 / 25(28 \cdot 0 \%)$; $\geqslant 55$ years, $4 / 12(33 \cdot 3 \%)$.

In age-matched groups (those aged $\geqslant 35$ years table 1) there were no statistically significant differences between patients with and without typical involuntary orofacial movements in terms of demographic characteristics or medication history. However, patients with orofacial dyskinesia were characterised by a significantly greater degree of mental handicap $(p<0.01)$ than those without such movement disorder. Seven of the 49 patients with mental handicap had no record of exposure to neuroleptics. Two of these (one male and one female; aged 47 and 53 years) showed typical orofacial dyskinesia indistinguishable from that evident in neuroleptic-treated patients, and each was characterised by severe mental handicap (score 5). The remaining five patients ( 2 male, 3 female) were aged $41 \cdot 4$, SD 10.9 years.

Among 23 patients with epilepsy and also aged $\geq 35$ years, 15 had been exposed to neuroleptics (durations 0.2-23.7 years). Of these, four ( 2 male and 2 female; aged 59.5, SD 5.8 and treated with neuroleptics for $12 \cdot 3$, SD 9.4 years) showed typical orofacial dyskinesia, while 11 ( 7 male, 4 female; aged $56 \cdot 5$, SD 16.2) and treated with neuroleptics for $10 \cdot 6$, SD $8 \cdot 8$ years) did not. All four epileptic patients with orofacial dyskinesia showed evidence of organic brain dysfunction additional to their convulsive disorder; in two cases epilepsy was secondary to brain damage, and in two cases epilepsy was associated with marked intellectual impairment (scores of 2 and 3 on a 10-question mental test of orientation, awareness and immediate memory $\left.{ }^{1}\right)$. The remaining eight patients with epilepsy had no record of exposure to neuroleptics. Of these, one patient (male; aged 76) showed typical orofacial dyskinesia; he was intellectually impaired, with a mental test score of 5 . The other seven patients ( 6 male, 1 female; aged 51.6, SD 10.8 years) showed no such movement disorder.

\section{Discussion}

The prevalence of orofacial dyskinesia was found to increase with age in those patients who had received neuroleptic treatment. This is in agreement with two previous systematic studies of tardive dyskinesia in the mentally handicapped, ${ }^{910}$ with the majority of studies in heterogeneous groups of psychiatric (usually psychotic) patients, ${ }^{6}$ and with results from a homogeneous schizophrenic group. ${ }^{13}$

In age-matched groups, mentally handicapped patients with and without orofacial dyskinesia could not be distinguished in terms of a wide range of typical indices of their past and current exposure to neuroleptics and anticholinergics. However, those with such involuntary movements were characterised by a considerably greater degree of mental handicap. Of the two previous studies, one found no overall association between dyskinesia and degree of mental handicap, ${ }^{10}$ but the patient population was a mean of 15 years younger than our own and fell into a narrower range of handicap. In the second study, ${ }^{9}$ both severity of mental handicap and extent of prior exposure to neuroleptics were highly correlated with the emergence of prominent involuntary movements.

These results are generally similar to our findings in schizophrenic and bipolar affective patients, where those with orofacial dyskinesia were characterised by an excess of cognitive dysfunction and other neurological signs rather than by more vigorous or prolonged exposure to neuroleptics or anticholinergics. ${ }^{1-5}$ There is now an increasing body of evidence that involuntary movements in schizophrenia are more likely to occur in association with such putative signs of organic brain dysfunction. ${ }^{7}$ If greater severity of (heterogeneous) mental handicap crudely reflects greater cerebral dysfunction, ${ }^{14}{ }^{15}$ its association with the emergence of involuntary movements during neuroleptic treatment may be conceptually similar to that reported in schizophrenia and bipolar affective disorder (and epilepsy).

A recurring problem in research on tardive dyskinesia in schizophrenia has been that of defining the baseline prevalence of involuntary movements in the absence of exposure to neuroleptics. ${ }^{7}$ In the present population of the mentally handicapped, seven patients had no record of having received neuroleptics. Two of these, each with severe mental handicap, showed typical orofacial dyskinesia 
indistinguishable from that shown by their neuroleptic-treated counterparts; a similar case was noted among the epileptic group. They emphasise the difficulty in differentiating that component of involuntary movements deriving from neuroleptic treatment and that deriving from other aspects of cerebral dysfunction, ${ }^{7}$ whether they be neurodegenerative or neurodevelopmental in origin.

Neuroleptics may enhance, or cause to arise prematurely, a syndrome that appears to have an unappreciated likelihood of ultimately emerging spontaneously with increasing cerebral dysfunction. ${ }^{7}$ Irrespective of these considerations, there may be a substantial hazard to the use of neuroleptic drugs in the mentally handicapped. If they are deemed necessary, high doses and long-term use should be viewed with caution in relation to the likelihood of benefit. ${ }^{16}$

This work was supported by the Health Research Board and the Royal College of Surgeons in Ireland. We thank Dr P Horne for allowing us to assess patients under her care.

\section{References}

1 Waddington JL, Youssef HA. An unusual cluster of tardive dyskinesia in schizophrenia: association with cognitive dysfunction and negative symptoms. Am J Psychiatry 1986;143:1162-5.

2 Waddington JL, Youssef HA. Late onset involuntary movements in chronic schizophrenia: relationship of tardive dyskinesia to intellectual impairment and negative symptoms. Br J Psychiatry 1986;149:616-20.

3 Waddington JL, Youssef HA, Dolphin C, Kinsella A. Cognitive dysfunction, negative symptoms and tardive dyskinesia in schizophrenia: their association in relation to topography of involuntary movements and criterion of their abnormality. Arch Gen Psychiatry 1987;44:907-12.

4 Youssef HA, Waddington JL. Primitive (developmental) reflexes and diffuse cerebral dysfunction in schizo- phrenia and bipolar affective disorder: overrepresentation in patients with tardive dyskinesia. Biol Psychiatry 1988;23:791-6.

5 Waddington JL, Youssef HA. Tardive dyskinesia in bipolar affective disorder: aging, cognitive dysfunction, course of illness and exposure to neuroleptics and lithium. Am J Psychiatry 1988;145:613-6.

6 Kane JM, Smith JM. Tardive dyskinesia: prevalence and risk factors, 1959-1979. Arch Gen Psychiatry 1982;39:473-81.

7 Waddington JL. Tardive dyskinesia in schizophrenia and other disorders: associations with ageing, cognitive dysfunction and structural brain pathology in relation to neuroleptic exposure. Human Psychopharmacology 1987;2:11-22.

8 National Institute of Mental Health. Abnormal involuntary movement scale. In: Guy W, ed. ECDEU Assessment Manual. Rockville: US Department of Health, Education and Welfare, 1976.

9 Gualtieri CT, Schroeder SR, Hicks RE, Quade D. Tardive dyskinesia in young mentally retarded individuals. Arch Gen Psychiatry 1986;43:335-40.

10 Richardson MA, Haugland G, Pass R, Craig TJ. The prevalence of tardive dyskinesia in a mentally retarded population. Psychopharmacology Bulletin 1986;22: 243-9.

11 American Psychiatric Association. Diagnostic and Statistical Manual of Mental Disorders, 3rd edition. Washington: American Psychiatric Association, 1980.

12 Davis JM. Comparative doses and costs of antipsychotic medication. Arch Gen Psychiatry, 1976;33:858-61.

13 Waddington JL, Youssef HA. Late onset involuntary movements in chronic schizophrenia: age-related vulnerability to tardive dyskinesia independent of extent of neuroleptic medication. Ir Med J 1985;78:143-6.

14 Cowie V. Injury and insult: considerations of the neuropathological aetiology of mental subnormality. $\mathrm{Br} J$ Psychiatry 1980;137:305-12.

15 Sylvester PE. Ammon's horn or hippocampal sclerosis without epilepsy in mental handicap. $\mathrm{Br} J$ Psychiatry 1984;144:538-41.

16 Menolascino FJ, Stark JA. Handbook of Mental Illness in the Mentally Retarded. New York: Plenum Press, 1984. 